\title{
Abducens Nerve Palsy as Initial Manifestation of Chronic Subdural Hematoma: Case Report
}

\section{Paralisia do nervo abducente como manifestação inicial de hematoma subdural crônico: Relato de caso}

\author{
Marcelo José Silva Magalhães ${ }^{1,2,3}$ Henrique Nunes Pereira Oliva ${ }^{3}$ Getúlio Paixão Pereira ${ }^{3}$ \\ Lucas Gabriel Quadros Ramos ${ }^{3}$ Henrique Caires Souza Azevedo ${ }^{3}$ \\ ${ }^{1}$ Department of Neurosurgery, Hospital Vila da Serra, Belo Horizonte, \\ Brazil \\ 2 Faculdades Unidas do Norte de Minas, Montes Claros, MG, Brazil \\ ${ }^{3}$ Faculdades Integradas Pitágoras, Montes Claros, MG, Brazil \\ Address for correspondence Marcelo José da Silva de Magalhães, MD, \\ MSc, Rua Francisco Versiane Ataide, $n^{\circ} 760$, apartment $n^{\circ} 1301$., \\ Montes Claros, MG, 39401-039, Brazil \\ (e-mail: marcelo7779@yahoo.com.br).
}

Arq Bras Neurocir 2019;38:315-318.

\begin{abstract}
Keywords

- chronic subdural hematoma

- abducens nerve palsy

- cranioencephalic trauma

Chronic subdural hematoma (CSDH) is a form of progressive intracranial hemorrhage, typically associated with cases of trauma. The manifestation of this comorbidity with abducens palsy is a rare finding. The present work aims to describe the case of an adult patient with abducens nerve palsy as a manifestation of CSDH. Chronic subdural hematoma is most commonly found in elderly patients, with systemic hypertension as a manifestation. The relation with the sixth cranial nerve is unusual and draws attention to the case reported. In addition, the prognosis is positive, since trepanation and drainage surgery was performed, as it is recommended in the literature.

\section{Resumo}

Palavras-chave

- hematoma subdural crônico

- paralisia do nervo abducente

- traumatismo cranioencefálico

O hematoma subdural crônico (HSDC) é uma forma de hemorragia intracraniana de caráter progressivo, tipicamente associado a casos de traumatismo. A manifestação dessa comorbidade com paralisia do nervo craniano abducente é um achado raro. 0 presente trabalho visa descrever o caso de um paciente adulto com paralisia do nervo abducente como manifestação do HSDC. O HSDC é mais comumente encontrado em pacientes idosos, com manifestação de hipertensão arterial sistêmica. A relação com o sexto nervo craniano é incomum, e chama a atenção no caso relatado. Além disso, o prognóstico é positivo, uma vez que foi realizada cirurgia com trepanação e dreno, conforme recomendado na literatura.
\end{abstract}

\section{Introduction}

Chronic subdural hematoma (CSDH) is characterized as an encapsulated blood collection of different stages of degeneration, with well-defined limits and located between the dura mater and the arachnoid meninges. It is one of the most common forms of intracranial hemorrhage that can present a progressive and chronic character. ${ }^{1}$

The present study aims to describe a rare case of $\mathrm{CSDH}$ with initial manifestation of abducent nerve palsy, besides presenting a brief literature review of the topics related to the case herein studied. In order to do so, we used recent received

February 26, 2017

accepted

April 12, 2017
DOI https://doi.org/

10.1055/s-0037-1603107. ISSN 0103-5355.
Copyright $\odot 2019$ by Thieme Revinter

Publicações Ltda, Rio de Janeiro, Brazil
License terms

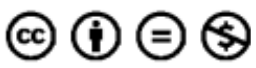


material made available in virtual libraries, in addition to the analysis of patient records with unusual case presentation.

The study was performed at Hospital Aroldo Tourinho, located in the municipality of Montes Claros, in the state of Minas Gerais, Brazil. A review of the medical records of the patient was first performed to write the case report. Then, we proceeded to the literature search for papers published in the past 35 years and written in Portuguese, English and Spanish. The inclusion criteria for the studies searched were: use of the appropriate methodology; current studies; and studies that shared any similarities with the present case. The exclusion criteria were: low relevance; articles not approaching the area of interest; and lack of essential information.

The following descriptors were used: chronic subdural hematoma, abducens nerve palsy and cranioencephalic trau$m a$. The databases accessed were the Scientific Electronic Library Online (SciELO) and the Virtual Health Library (VHL). The minhaUFMG web portal was also used to access paid articles on topics pertinent to the present research.

\section{Case Report}

Patient S.M.O., 35 years old, male and farmer, presented with mild cranioencephalic trauma that had occurred approximately in the preceding 2 months, due to a motorcycle crash while wearing a helmet. He sought outpatient medical care due to diplopia and persistent headache, which resolved $\sim 30$ days after the accident. A magnetic resonance imaging (MRI) scan of the skull evidenced the presence of a bulky chronic subdural hematoma in the right frontoparietal convexity, with a hypersignal aspect in $\mathrm{T} 1$ and heterogeneous isosignal in T2. This hematoma caused a mean line deviation of $1.1 \mathrm{~cm}$ and presented the following dimensions: $12.0 \times 6.4 \times 2.0 \mathrm{~cm}$ (length $\mathrm{x}$ width $\mathrm{x}$ depth), totaling $65 \mathrm{~mL}$ (-Figs. 1a and 1b). Upon neurological examination, we identified the presence of paresis of the abducens nerve on the left (-Fig. 2 ) side. On the right side, the consensual pupillary reflex was present. There were no

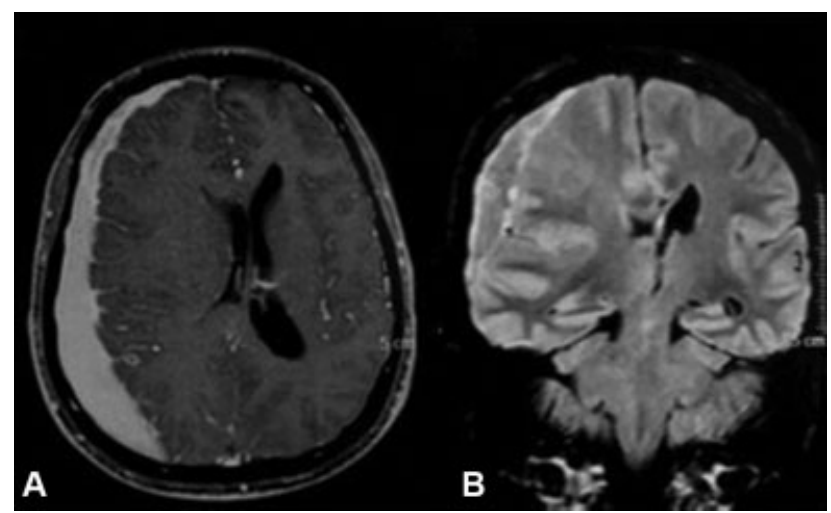

Fig. 1 (A) T1-weighted magnetic resonance imaging (MRI) scan of the skull in axial section following contrast with gadolinium. Note the presence of bulky subdural hematoma in the right convexity causing mass effect. (B) T1-weighted sequence of MRI of the skull in coronal section revealing a bulky subdural hematoma in the right convexity. Observe the mass effect with evidence of herniation of the cingulate gyrus.

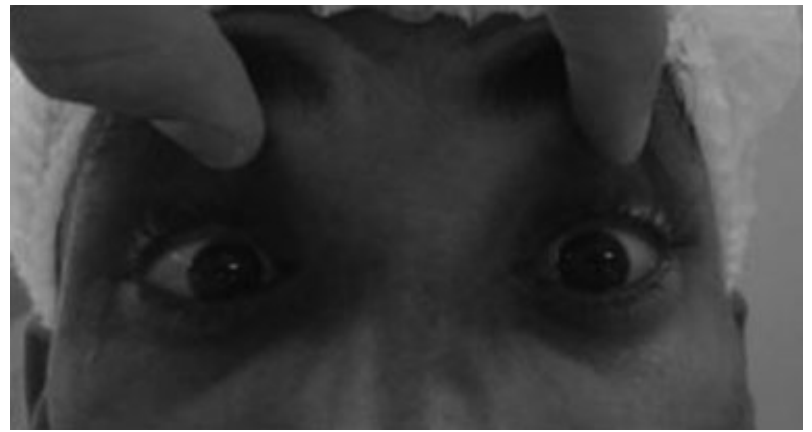

Fig. 2 Photo of the patient moments before the surgical procedure. Observe the presence of convergent strabismus due to the paresis of the abducens nerve to the right.

alterations in the cerebellar evidence. On the motricity examination, the presence of hemiparesis of degrees 4/5 was observed in the left dimidium. Fundoscopy showed the presence of bilateral optic papilla edema. Conscious alert, oriented and euphasic. After the examination, the patient was urgently hospitalized, , and surgical risk exams were requested. He was submitted to neurosurgical treatment through the trepanation technique in the frontal and parietal bones using a surgical drain. The drain was removed after 24 hours of the surgical procedure, and the patient was discharged 48 hours after surgery. In a return consultation, performed 30 days after the surgical procedure, the patient presented complete recovery of the paresis of the oculomotor nerve.

\section{Discussion}

The first case of CSDH was reported in 1657 by Johannes Wepfer. A blood-filled cyst was found in the subdural space in a patient who died after a vascular accident. About 9 years later, Morgagni reported a similar finding in a patient who had also died after a vascular accident. In 1817, Houssard described this cyst as a clot wrapped in a membrane. Bayle, in 1826, described CSDH physiopathology as a chronic rebleeding. Chronic subdural hematoma was considered a type of cerebrovascular accident (CVA) in the 17th century, an inflammatory disease in the 19th century, and, in the 20th century, the consequence of a traumatic injury. Only in the end of the 20th century there was a consensus on the current theory of $\mathrm{CSDH}$, which consists of a chronification of an asymptomatic acute subdural hematoma, in which there are microhemorrhages in the external region of the formed membrane, which are responsible for the growth of what would become the CSDH mechanism that Markwalder ${ }^{2}$ commented in his review of the subject. ${ }^{3}$

Two theories have been proposed to clarify the development of CSDH: the osmotic theory and the theory of recurrent bleeding in an encapsulated hematoma. ${ }^{4}$ The osmotic theory is basically explained by coagulation and posterior degradation of extravasated blood into the subdural space. This degradation would generate a greater number of proteins, increasing osmotic pressure and creating a greater difference in the concentration gradient that would attract fluids of adjacent blood vessels to the hematoma cavity. ${ }^{5}$ 
However, the most well-accepted and proven theory is the recurrent bleeding theory, which describes the abnormality and dilation of the blood vessels of the hematoma capsule as a source of recurrent bleeding. ${ }^{1,4}$

The most frequent cause of CSDH is trauma, characterized by a sudden process of acceleration and deceleration of the skull, to the point of generating a displacement of the encephalon and rupture of the bridge veins. ${ }^{6-8}$

Chronic subdural hematoma is commonly found in the elderly, and it is usually bilateral, especially in those older than 75 years of age. In young adults, CSDHs are relatively infrequent and, unlike those in the elderly, are almost always unilateral. ${ }^{9}$ Since one of the risk factors is age, which is not modifiable, its incidence may reach 58 cases for every 100,000 people per year in age groups of people older than 70 years, while in the general population it is of $\sim 5$ cases for every 100,000 people per year. ${ }^{1}$

The most used exams for CSDH evaluation are computed tomography (CT) and MRI of the skull, since they detect various characteristics of the hematoma, such as the intensity of the lesion, presence of recurrence, and the patient's hematocrit status. ${ }^{9,10}$

Computed tomography is the least innocuous imaging method, but it is faster and has a lower cost. Some cranial CT findings are the deviations of structures in the median line and cerebral herniations. The blood collection usually presents as homogeneous and hypoattenuating in the CT; if there is any new bleeding, the new collection will present as hyperdense. ${ }^{11}$

The MRI provides more accurate information about the location and extent of the hematoma and its effect on adjacent structures. In cases of isodense and bilateral hematomas, if small collections at the base of the skull and in the posterior fossa are found, the MRI is even more advantageous. ${ }^{10}$

The signs and symptoms of the patient may be diverse, as they depend on certain factors such as: size and location of the hematoma, age of the patient, and whether it is unilateral or bilateral. Some of the most recurrent symptoms of this disease are: hemiparesis, sudden hemiplegia, and progressive headache without improvement with the use of simple analgesia. ${ }^{12}$ In a study ${ }^{13}$ conducted between 1971 and 1987 with 96 surgical cases of CSDH, the following symptoms were present in order of prevalence: headache (69.8\%), focal motor deficit (62.5\%), dementia syndrome (38.5\%), torpor (28\%), urinary incontinence (19.8\%), coma (14.5\%), ataxia (11.5\%), convulsive crises (5\%) and aphasia (5\%). ${ }^{13}$

Oculomotor nerve palsy as one of the initial clinical manifestations of CSDH is rare, but some cases are found in the literature. This paralysis is responsible for causing palpebral ptosis on the affected side and diplopia. In the case of unilateral lesions of the third cranial nerve, a differential diagnosis of microvascular infarction and intracranial aneurysm should be performed. ${ }^{14}$

The abducens nerve is the sixth pair of cranial nerves, responsible for innervating only the lateral rectus, for abduction of the ocular globe. ${ }^{15}$ Motoneurons originate in the abducens nucleus, which is located in the caudal and dorsal regions of the bridge, and leave the nucleus ventrally to form the abducens nerve fibers in the brainstem. This cranial nerve leaves the brainstem at the junction between the bridge and the bulb to enter the subarachnoid space. It is noted that the nerve then makes an acute angle before turning and ascending over the clivus at the petrous apex. It passes under the petroclinoid ligament and penetrates the Dorello canal, where the dural connection makes it vulnerable to the change in intracranial pressure and trauma. Then, this nerve crosses the cavernous sinus, adjacent to the internal carotid artery. ${ }^{15,16}$ Abducens nerve lesions result in unilateral involvement of the eye abduction, in addition to horizontal diplopia and deviation of the eye toward the nose, being worse in the direction of action of the affected lateral rectus. ${ }^{15}$ In addition, abducens nerve palsy is reported as the most common cranial neuropathy to occur in isolation. ${ }^{17}$ The main etiologies are: trauma, neoplasia, cerebrovascular disease and cerebral aneurysms. ${ }^{15}$

There are other cases of abducent nerve palsy reported in the literature with favorable prognosis. There is a good margin of recovery of the physiological activity of the sixth cranial nerve, and the total recovery rate can reach up to $73 \%$ within 6 months, when the CSDH is unilateral, and the mean recovery time is 3 months. ${ }^{18}$

There are several possibilities of conservative treatment described in the medical literature for CSDH: extreme rest, corticoids and hypertonic solutions. ${ }^{1,9}$ However, clinical treatment is not the best indication, since the surgical procedure has been accepted worldwide as a more efficient method. ${ }^{1}$

There are several types of surgical treatment for CSDH, such as craniotomy, trepanation and endoscopy. Craniotomy is indicated when the blood collection membrane is calcified, and not liquefied, ossified, organized or multiloculated. Trepanation is one of the most efficient choices when the CSDH will not be removed; one or two trepanations can also be performed, and the performance of two is associated with a better postoperative evolution. The endoscopic treatment is a safer way to perform the removal of the CSDH, and it is indicated when the blood collection is solid, organized and multiloculated, because it guarantees a direct view of it. ${ }^{19}$

The use of drains in the trepanation orifice in the postoperative period is associated with a reduction in the number of recurrences of the subdural hematoma. In a randomized study conducted in the United Kingdom with 269 patients older than 18 years of age, the recurrence rate in patients with drains was of $9.3 \%$, while in patients without drains it was of $18.1 \% .^{20}$

\section{Conclusion}

When compared with other cases found in the neurosurgery routine practice, $\mathrm{CSDH}$ is a disease associated with significant rates of morbidity and mortality. As described, the most frequent clinical alterations are systemic arterial hypertension and altered consciousness. The case is especially rare when it presents involvement of the abducens nerve, even when the cause is not uncommon, that is, trauma. Trepanation with double orifices and drainage confirmed the effectiveness reported in the literature, and it is the most indicated technique, 
which did not involve complications in the present case. The patient presented a good prognosis, with improvement of the symptoms 1 month after the surgical intervention.

\section{Conflict of Interests}

The authors have none to declare.

\section{References}

1 Farhat Neto J, Araujo JL, Ferraz VR, Haddad L, Veiga JC. Chronic subdural hematoma: epidemiological and prognostic analysis of 176 cases. Rev Col Bras Cir 2015;42(05):283-287

2 Markwalder TM. Chronic subdural hematomas: a review. J Neurosurg 1981;54(05):637-645

3 Lee KS. History of Chronic Subdural Hematoma. Korean J Neurotrauma 2015;11(02):27-34

4 Miranda HRA, Alcalá-Cerra G, Rubiano AM, Moscote-Salazar LR. Hematoma subdural crónico: Fisiopatología y Manejo Quirúrgico. Boletín Médico Científico de la Asociación Médica de Puerto Rico; 2014

5 Mateos FRN. Análisis de factores pronósticos en los pacientes intervenidos de Hematoma Subdural Crónico. 2013. 157 p. Salamanca, Espanha: Tese (Doutorado) Departamento de Cirurgía da Universidad de Salamanca; 2013

6 Sousa EB. Perfil epidemiológico dos pacientes submetido à drenagem de hematoma subdural crônico no distrito federal: uma análise de uma série monocêntrica 778 pacientes. Março de 2013. 92 p. Brasília, DF: Dissertação (Mestrado) - Faculdade de Ciências Médicas da Universidade de Brasília; 2013

7 Lee YJ, Barker R. An unusual cause of back pain in a child: spinal subdural haematoma secondary to intracranial arachnoid cyst haemorrhage. Quant Imaging Med Surg 2016;6(04):478-481

8 Chhabra S, Gupta A. Chronic subdural hematoma associated with idiopathic thrombocytopenic purpura in an elderly female: A rare case report. Roman Neurosurg 2016;30(03):419-424
9 Gelabert-González M, Román-Pena P, Arán-Echabe E. Chronic subdural hematoma in the oldest-old population. Neurosurg Rev 2018;41(04):983-984

10 Senturk S, Guzel A, Bilici A, et al. CT and MR imaging of chronic subdural hematomas: a comparative study. Swiss Med Wkly 2010;140(23-24):335-340

11 Gattás GS. Imagem no traumatismo craniano. Rev Med (São Paulo) 2011;90(04):157-168

12 Pereira CU, Junior JASJ, Santos ACL, Passos RO. Hematoma subdural crônico em adultos jovens. Arq Bras Neurocir 2015;34(01): 25-29

13 Salomão JF, Leibinger RD, Lynch JC. [Chronic subdural hematoma: surgical treatment and results in 96 patients]. Arq Neuropsiquiatr 1990;48(01):91-96

14 Matsuda R, Hironaka Y, Kawai H, Park YS, Taoka T, Nakase H. Unilateral oculomotor nerve palsy as an initial presentation of bilateral chronic subdural hematoma: case report. Neurol Med Chir (Tokyo) 2013;53(09):616-619

15 Elder C, Hainline C, Galetta SL, Balcer LJ, Rucker JC. Isolated Abducens Nerve Palsy: Update on Evaluation and Diagnosis. Curr Neurol Neurosci Rep 2016;16(08):69

16 Wysiadecki G, Orkisz S, Gałązkiewicz-Stolarczyk M, Brzeziński P, Polguj M, Topol M. The abducens nerve: its topography and anatomical variations in intracranial course with clinical commentary. Folia Morphol (Warsz) 2015;74(02):236-244

17 Rush JA, Younge BR. Paralysis of cranial nerves III, IV, and VI. Cause and prognosis in 1,000 cases. Arch Ophthalmol 1981;99(01): 76-79

18 Salunke P, Savardekar A, Sura S. Delayed-onset bilateral abducens paresis after head trauma. Indian J Ophthalmol 2012;60(02): 149-150

19 Yadav YR, Parihar V, Namdev H, Bajaj J. Chronic subdural hematoma. Asian J Neurosurg 2016;11(04):330-342

20 Santarius T, Kirkpatrick PJ, Ganesan D, et al. Use of drains versus no drains after burr-hole evacuation of chronic subdural haematoma: a randomised controlled trial. Lancet 2009;374(9695):1067-1073 